\title{
CONTINUOUS EPIDURAL ANALGESIA FOR LABOUR AND DELIVERY*
}

\author{
J. S. NielsêN, L.R.C.P., M.R.C.S., W. E. Spoerel, M.D., F.R.C.P.(C.), \\ H. B. Keenleyside, M.D., P. E. Slater, M.D., and P. R. Clancy, M.D.
}

THE USE OF conduction anaesthesia in child-birth requires an understanding of the nerve supply of the uterus and birth canal. According to Cleland ${ }^{1}$ the motor and sensory elements of the autonomic nerve supply are arranged in the following way: Apart from an intrinsic motor mechanism, motor fibres from the segments $\mathrm{T} \pm$ to $\mathrm{T} 10$ and possibly some from the upper lumbar segments are carried in the sympathetic pathways to the body of the uterus; sensory fibres from the uterus enter the spinal cord of T11 and T12. The sacral plexus supplies sensory fibres to the birth canal. Sacral parasympathetic fibres also initiate the reflex response of "bearing down" during the second stage of labour. This arrangement of nerve supply makes it possible to obtain analgesia without significant interference with the motor activity of the uterus. Thus, a paravertebral block of T11 and T12 was used by Cleland ${ }^{1}$ during the first stage of labour. Jarvis ${ }^{8}$ reporterd the use of continuous paravertebral technique with adequate results in 85 per cent of cases; in some of these anaesthesia was sufficient for delivery, presumably owing to the spread of local anaesthetics to the sacrall roots.

The use of two catheters in the epidural ppace was advocated by Cleland ${ }^{2}$ in 1947: a lumbar epidural catheter provides a block of the sensory supply to the uterus while a caudal catheter is used to anaesthetize the birth canal for delivery. A description of this technique is contained in texts, on regional anaestheşia..$^{9.10}$

Since then lumbar epidural analgesia has become a popular method, particularly to provide analgesia for the second stage of labour and delivery. ${ }^{3,46}$ Its use during the first stage of labour is not generally accepted and there has been no report of deliberate use of a method using a single lumbar epidural catheter to provide both analgesia during the first stage of labour and anaesthesia for delivery.

The following represents an analysis of our results with such a method as well as an attempt to evaluate its effect on the progress of labour and the delivery.

\section{TEChNique}

The 213 cases in this report were under the care of five anaesthetists who had a similar plan of producing analgesia, but unavoidably some individual modifications occurred. In principle, however, the technique used was as follows: A polyvinyl catheter was introduced through a Tuohy needle (gauge 17) into an upper lumbar interspace (loss of ressistance technique) with the patient in the

*From Departnient of Anaesthesia, University of Western Ontario, and Victoria Hospital and St. Joseph's Hospital, 'London, Ontario.

Can. Anaes. Soc. Jo vol, 9 , no. 2, March, 1962 
usual lateral position. This catheter was taped securely to the back and injections of Xylocaine ( 1 per cent or 1.5 per cent with or without adrenaline) or Carbocaine ( 1 per cent) were made at suitable intervals with the patient in the supine position. The volume of local anaesthetic was kept small (Table I) with the aim

TABLE I

Volume of Xylocaine Used for Continuous Epidural Analgesia

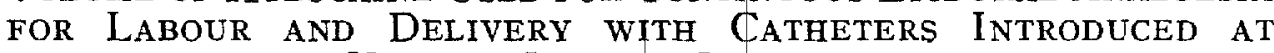
VARIOUS LUMBar INTERSPaCES

\begin{tabular}{|c|c|c|c|c|}
\hline \multirow[b]{2}{*}{ Interspace } & \multicolumn{2}{|c|}{ Labour } & \multicolumn{2}{|c|}{ Delivery } \\
\hline & $\begin{array}{l}\text { No. of } \\
\text { cases }\end{array}$ & $\begin{array}{c}\text { Volume } \\
\text { (average), } \\
\text { ml. }\end{array}$ & $\begin{array}{l}\text { No. of } \\
\text { cases }\end{array}$ & $\begin{array}{c}\text { Volume } \\
\text { (average) } \\
\text { ml. }\end{array}$ \\
\hline $\begin{array}{l}\text { T12/L1 } \\
\text { L1/L2 } \\
\text { L2/L3 } \\
\text { L3/L4 } \\
\text { L4/L5 }\end{array}$ & $\begin{array}{r}4 \\
32 \\
75 \\
49 \\
2\end{array}$ & $\begin{array}{ll}6 & 0 \\
6 & 4 \\
5 & 5 \\
7 & 3 \\
6 & 0\end{array}$ & $\begin{array}{r}4 \\
32 \\
82 \\
53 \\
2\end{array}$ & $\begin{array}{ll}16 & 3 \\
14 & 4 \\
14 & 5 \\
13 & 7 \\
10 & 0\end{array}$ \\
\hline
\end{tabular}

of producing a sensory block of the upper lumbar and the lowest thoracic roots and of avoiding anaesthesia of sacral roots. Such a block should give a skin anaesthesia to a level between umbilicus and symphysis, with skin analgesia of the legs corresponding to the upper lumbar segments.

A larger volume of anaesthetic solution (1.5 to 2 per cent Xylocaine or 1 per cent (arbocaine) was injected after full dilatation of the cervix to obtain analgesia of the birth canal (Table I). The spread of the anaesthetic agent in the epidural canal was aided by having the patient sit up during the injection or placing her in a head-up position.

\section{Selection of Patients}

The technique described was used in 160 primiparae and 53 multiparae. The analgesia was in all cases requested by the obstetrician, in the majority of cases at a time when the uterine contractions had become sufficiently painful that an analgesic drug was required; in some instances the patient had a small dose of the routinely used combinations of analgesic drugs before the start of epidural analgesia.

To demonstrate the use of epidural analgesia early in labour, we have compared the degree of cervical dilation in 92 primiparae at the beginning of epidural analgesia with a frequency distribution reported by Flowers et al..$^{5}$ relating the necessity for analgesic medication with the degree of cervical dilatation (Fig. 1). The frequency distribution of the two series is strikingly similar.

\section{RESULTS}

The effect of epidural analgesia for labour and for delivery was classified as follows:

Good: The patient was pain-free and received no sedation during labour or supplementary anaesthesia for the delivery. 
$\%$ of

coses of

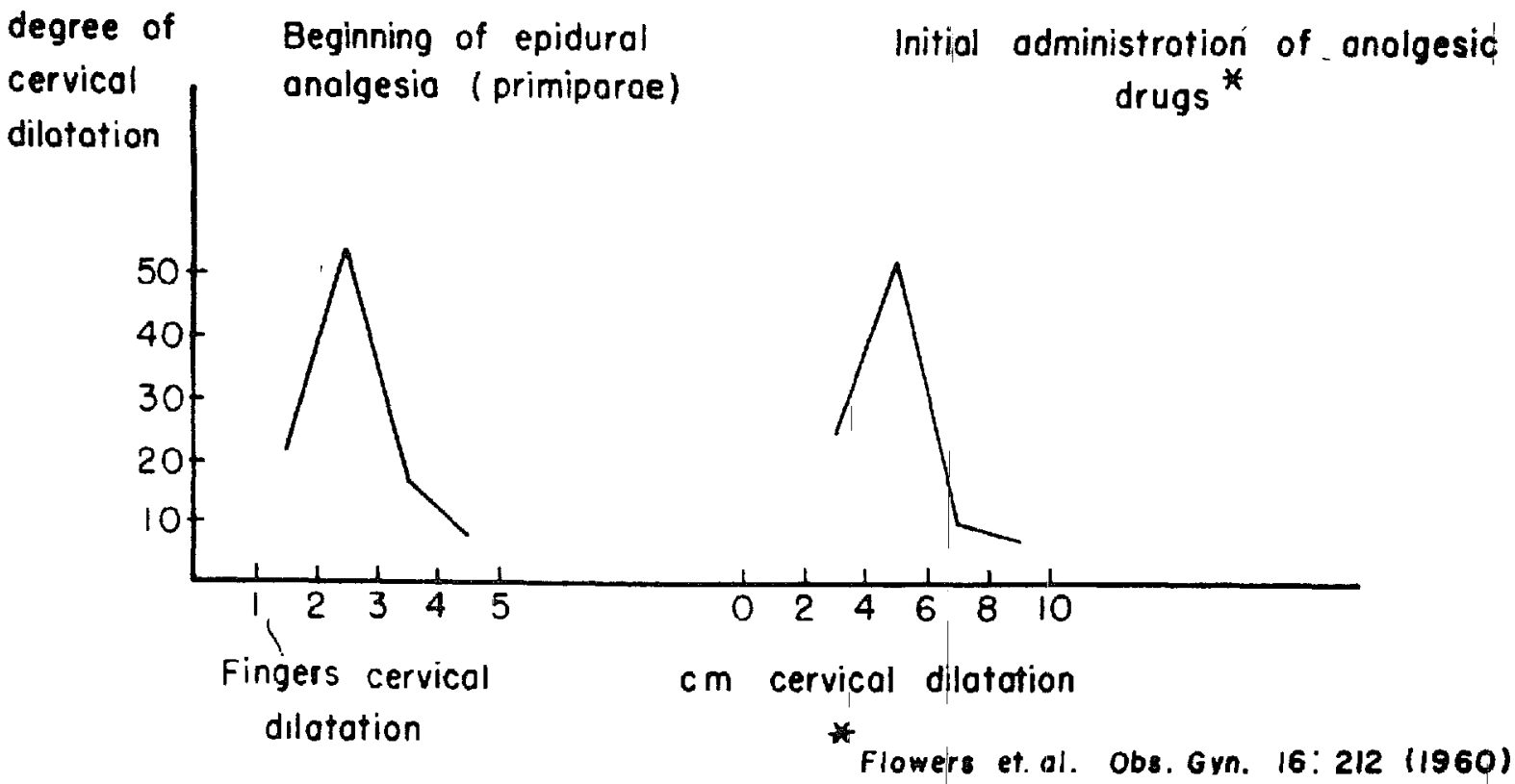

FIGURE 1. Distribution of primiparae according to degree of cervical dilation at the beginning of epidural analgesia; note the similarity to a distribution of cases in regard to the initial administration of analgesic drugs by Flowers $e t a l$.

Fair: Analgesic medication during labour or supplementary anaesthesia for delivery was required.

Failure: There was no evidence of an epidural block despite proper technique.

The result of the epidural block for labour (Table II) was considered good in 182 cases ( 85 per cent). Of the remaining 31 cases, 16 had fair results and in 14 the result was not clearly stated in the records. There was one failure.

TABLE II

Results of Continuous Epidural Analgesia in Labour and FOR DELIVERY

\begin{tabular}{lclr}
\hline In labour & No. of cases & In delivery & No. of cases \\
\hline Good & \multirow{2}{*}{182} & Good & 159 \\
& & Fair & 15 \\
& & Failure & 5 \\
Fair & \multirow{2}{*}{16} & Not stated & 3 \\
& & Good & 6 \\
& & Fair & 7 \\
Failure & & Failure & 2 \\
Not stated & 1 & Not stated & 1 \\
& 14 & Failure & 1 \\
& & Good & 5 \\
& & Not stated & 9 \\
\hline
\end{tabular}

The analgesia was good for delivery in 170 cases ( 80 per cent) with fair results in 22 cases (10 per cent) and 8 failures ( 4 per cent). The records were incomplete in 13 cases.

A review of the inadequate results showed that the majority of them were due to faults in the handling of the continuous method; in most of these cases the 
epidural analgesia had been attended by an obstetrician or an intern not familiar with the procedure. In a number of cases the following errors could be established from the records:

1. The time interval between injections was too long or the block was allowed to lapse.

2. The volume injected was inadequate.

3. The time between epidural injections $\mid$ and the delivery was too short to allow a complete block to develop.

Of the 16 fair results during labour, 10 were obviously due to inadequate maintenance of the block. The inadequate results for delivery could be attributed to the errors listed above in 17 out of 30 cases.

It should be appreciated that the good results reported are fewer than the true results, since our records were incomplete in 6.5 per cent of our material. It is obvious that the results could be improved with a better management of the continuous epidural analgesia by qualified anaesthetists.

In the remaining cases the unsatisfactory result cannot be readily explained. One possible source of failure may be the position of the catheter. ${ }^{7}$ We found that in two-thirds of our fair results and failures, the catheter had been introduced in a caudad direction; in the whole series the catheter was directed caudad in only 30 per cent, which would give this technique a considerably higher rate of incomplete blocks.

\section{Complications}

Hypotension requiring the use of vasopressors was seen in 32 cases (15 per cent). It occurred with one exception when larger volumes were injected, equivalent to those used for delivery. The small volumes used for analgesia during labour did not produce serious falls in blood pressure. No significant effect on the foetus was observed in these 32 cases (Table VI).

An accidental subarchnoid puncture was made in two patients. In both an epidural catheter was introduced and the procedure continued uneventfully. One patient suffered from spinal headache for 5 days; in the other, $25 \mathrm{ml}$. of normal saline was injected epidurally before removal of the catheter and this patient had no headache.

A number of unusual responses were observed:

One patient developed anaesthesia to the level of $T 6$ following an injection of $15 \mathrm{ml}$. of 1.5 per cent Xylocaine in the sitting position. The perineal anaesthesia was incomplete.

In one patient the block was strictly unilateral in the perineal area and supplemental general anaesthesia had to be used for the forceps delivery.

In one patient the injection of $9 \mathrm{ml}$. of 1 per cent Carbocaine through a catheter in the interspace L1 and L2 did not provide pain relief nor detectable skin analgesia after 25 minutes; then $5 \mathrm{ml}$. of 2 per cent Xylocaine injected through the same catheter provided good analgesia.

Following an injection of $4 \mathrm{ml}$. of 1.5 per cent Xylocaine with $1: 200,000$ adrenaline one patient became drowsy and pale and hypotension was noted. She responded readily to methedrine and oxygen by mask. On questioning she 
recalled a similar attack at the dentist's some years ago; adrenaline was considered responsible at that time. Novocaine had been used for two previous deliveries without complications. A similar volume of 1.5 per cent plain Xylocaine was injected one hour later, resulting again in pallor and drowsiness. Subsequently 1 per cent Carbocaine was given through the same catheter without untoward effect and adequate analgesia was obtained for labour and delivery.

\section{EFFECT ON LABOUR}

Epidurál analgesia has been blamed for retarding labour, and increasing the incidences of abnormal positions of the foetus and the necessity for Caesarian sections. Following an injection for analgesia a transient slowing and weakening of the uterine contraction may occur, though contractions usually remain strong and effective. Frequently an inexperienced nurse will associate the lack of response of the patient.with a cessation or reduction of uterine contractions.

An analysis of the duration of epidural analgesia relative to the duration of labour was possible in 92 primiparae (Fig. 2). The longer labour time in the cases

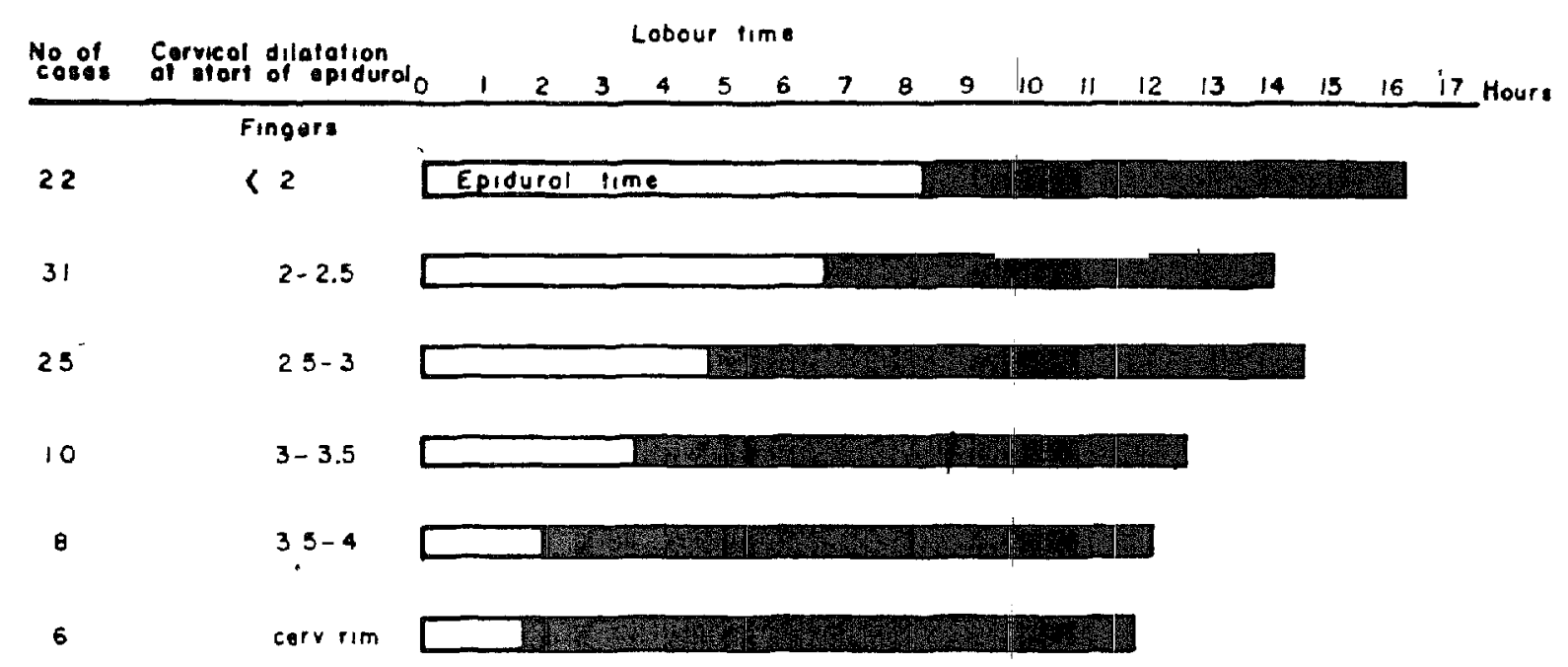

FIGURE 2. Epidural time and total labour time in 92 primiparae according to the degree of cervical dilatation at the beginning of epidural analgesia. Epidural time, white; duration of labour before epidural analgesia, black.

of an early epidural injection was as much related to the longer duration of labour before the beginning of epidural analgesia as to a longer time under epidural analgesia. However, the differences in duration of labour are not significaht in our series. Furthermore, it should be recalled that our cases have been selected on the basis of the discomfort of the mother; patients with difficult labour are likely to experience pain at an earlier stage of cervical dilation. This same factor of selection may be present in a comparison of the duration of labour in our cases with the duration in all the deliveries of the year 1959 (Fig. 3). In the groups over 10 hours the proportion in the epidural cases exceeded the proportion in the total maternity cases, but to a significant degree only in the group over 20 hours. This difference was due to the cases with Caesarian section.(Table III).

The duration of epidural analgesia from the introduction of the catheter to the delivery of the infant is shown in Table IV; while in the majority of cases 
$\%$ OF

CASES

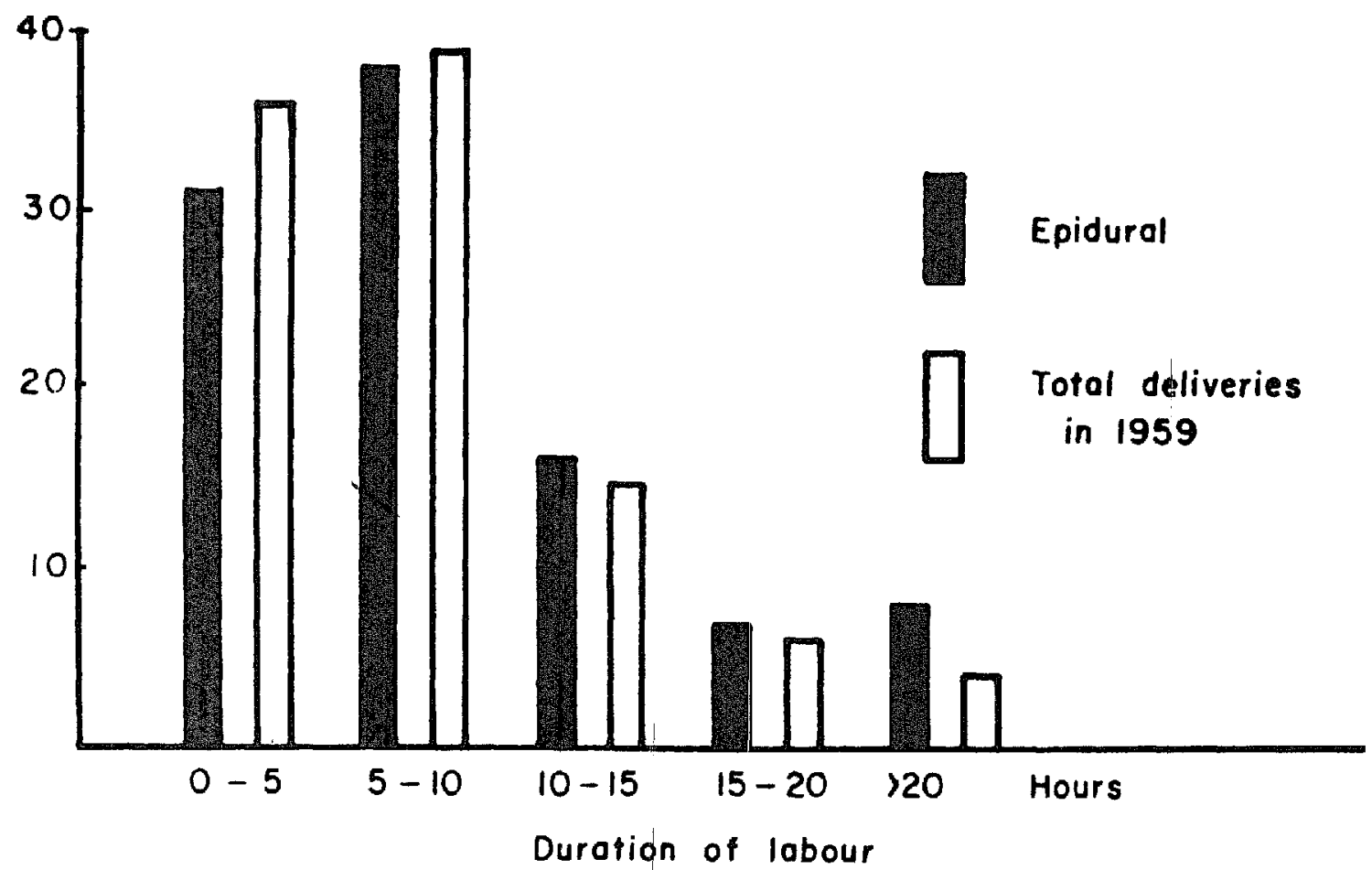

FIGURE 3. Distribution of cases according to duration of labour. Comparison between epidural series and total deliveries in 1959 (Victoria Hospital).

TABLE III

Indication for Caesarian Section and Duration of Labour before Beginning of Epidural ANALGEsia

\begin{tabular}{lccc}
\hline \multicolumn{1}{c}{ Indication } & No. of cases & $\begin{array}{c}\text { Average duration of labour } \\
\text { before epidural began, } \\
\text { hours }\end{array}$ & $\begin{array}{c}\text { Range } \\
\text { hours }\end{array}$ \\
\hline $\begin{array}{l}\text { Primiparae } \\
\text { Cephalo-pelvic disproportion }\end{array}$ & 7 & 195 & $5-305$ \\
$\quad \begin{array}{l}\text { Uterine inertia } \\
\text { Foetal distress }\end{array}$ & 3 & 285 & $23-32$ \\
$\quad$ Frank breech, trial labour & 1 & 33 & \\
Multiparae & & 12 & \\
$\quad \begin{array}{l}\text { Failure of head to descend } \\
\text { Bandl's ring-patient cardiac }\end{array}$ & 1 & 1 & \\
$\quad$ Uterine inertia, trial labour & 1 & 5 & \\
Total & 15 & & \\
\hline
\end{tabular}

it was less than 4 hours, it was maintained in one case for 26 hours, resulting in an uneventful vaginal delivery.

\section{TyPe of Deliveŕy}

Under epidural analgesia almost all deliveries were completed by forceps (Table V). This reflects the principles of the obstetricians whose patients were included in this series. A comparison with the maternity cases at Victoria Hospital in 1959 shows that forceps were used in over half of the vaginal deliveries.

The incidence of Caesarian sections was 7 per cent ( 15 cases) in our series; in 1959 the rate of Caesarian sections for Victoria Hospital was 4.8 per cent. The 
TABLE IV

Duration of Continuous Epìdural Analgesia and Caesarian SECTIONS

\begin{tabular}{lccc}
\hline \hline & Primiparae & Multiparae & $\begin{array}{c}\text { Caesarian } \\
\text { sections }\end{array}$ \\
\hline$<4$ hours & $75(47 \%)$ & $35(66 \%)$ & 1 \\
$4-10$ hours & $59(37 \%)$ & $8(15 \%)$ & 10 \\
$10-18$ hours & $20(13 \%)$ & $2(4 \%)$ & 4 \\
$18-26$ hours & $5(3 \%)$ & $3(6 \%)$ & 0 \\
Incomplete records & 1 & 5 & \\
Total & $160(100 \%)$ & $53(100 \%)$ & 15 \\
\hline
\end{tabular}

\section{TABLE $V$}

Type of Delivery with Continuous Epidural Analgesia Compared with All Deliveries in 1959 at Victoria Hospital

\begin{tabular}{lcc}
\hline & $\begin{array}{c}\text { Deliveries under } \\
\text { epidural analgesia }\end{array}$ & All deliveries 1959 \\
\hline Spontaneous & $4(1.9 \%)$ & $1190(43.4 \%)$ \\
Forceps & $191(90.0 \%)$ & $1272(47.5 \%)$ \\
Breech & $3(1.4 \%)$ & $76(2.8 \%)$ \\
Caesarian & $15(7.0 \%)$ & $129(4.8 \%)$ \\
Total & 213 & 2681 \\
\hline
\end{tabular}

indications for sections are shown in Table III. Most of these patients had been long in labour and the possibility of a Caesarian section had been considered before the epidural analgesia was started. This finding speaks against the assumption that the epidural analgesia was responsible for the higher section rate; rather this technique was selected more frequently in patients that had not had a satisfactory progress of labour. Also the distribution of Caessarian section in relation to the duration of epidural analgesia did not support this assumption; rather patients have been subjected to longer periods of trial labour under epidural analgesia.

The condition of the infants in our series as judged by the Apgar rating compares well with other methods (Table VI). There was no noticeable difference in the condition of the infant if the mother had a brief episode of hypotension during delivery.

TABLE VI

Condition of Infant with Continuous Epidural Analgesia Compared with Hospital Deliveries in 1959 and Cases with Combination of Sedation and Regional ANalgesia IN 1959 (VICTORIA Hospital, LONDON)

\begin{tabular}{ccccc}
\hline \hline Apgar rating & $\begin{array}{c}\text { Epidural, } \\
\text { no. of cases }\end{array}$ & $\begin{array}{c}\text { Epidural with } \\
\text { hypotension episode }\end{array}$ & $\begin{array}{c}\text { All } \\
\text { deliveries* }\end{array}$ & $\begin{array}{c}\text { Sedation and } \\
\text { regional } \\
\text { anaesthesia* }\end{array}$ \\
\hline $9-10$ & $177(83 \%)$ & $24(75 \%)$ & $74 \%$ & $78 \%$ \\
$7-8$ & $23(11 \%)$ & $7(22 \%)$ & $18 \%$ & $16 \%$ \\
$5-6$ & $7(3 \%)$ & $1(3 \%)$ & $5 \%$ & $4 \%$ \\
$<4$ & 0 & 0 & $2 \%$ & $1 \%$ \\
No record & 6 & & & \\
\hline
\end{tabular}

*Victoria Hospital 1959. 


\section{Discussion}

Continuous epidural analgesia appears to be superior to other forms of analgesia in regard to both mother and infant. A block of the sensory nerve supply to the uterus provides a condition where the mother is comfortable, though fully aware of having contractions. The reflexes mediated by the sacral roots are intact and the urge to "bear down" is fully retained, once the cervix is dilated. The change in appearance of the mother before and after the induction of epidural analgesia is striking: apparently exhausted from hours of painful labour, the pain relief of the block brings relaxation and comfort, which improves the physical and mental condition of the mother. The condition for instrumental delivery is ideal and the hazards of general anaesthesia are avoided.

It has been the impression of our nurses that these patients have more discomfort in the immediate post-partum period. The blockade of pain with a nerve block usually leads to a return of such pain with greater strength after the block has worn off. The patient with a continuous block will also be at a disadvantage in comparison with a patient treated with repeated doses of long-acting analgesic. This disadvantage can be overeome easily by the administration of an analgesic before the block has worn off. It is also said that these patients have a higher incidence of urinary retention. This aspect has not been included in our study but requires thorough investigation.

The infant is certainly not depressed by this form of analgesia and we did not find indications that the occasional episodes of hypotension had affected the baby. However, an occasional case of unexpected foetal distress becoming evident at the time of delivery should give rise to a more critical evaluation, particularly in view of the possibility of transient hypotensive periods that may go unnoticed unless the mother is constantly under expert observation.

This study demonstrates that the efficiency of this method can be most markedly improved through the management of the technique by anaesthetists familiar with continuous epidural analgesia. Our failure rate would have been less than one-half of that reported if we had been able to give these patients our full attention, particularly during the second stage of labour. The problem of anaesthetic coverage for obstetrical floors is common and we hope that our findings may stimulate us and others to improve the conduct of obstetrical anaesthesia.

Our results do not support the view that epidural analgesia shortens labour nor did we get evidence of a prolongation of labour, though we admit that individual cases may give us impressions in both directions. The most difficult task appeared to be to find suitable controls for comparison; our attempt to use the maternal hospital population for one year has the advantage of an identical obstetrical management but is far from ideal for other reasons. It is our impression that our series has been influenced by a tendency to request epidural analgesia for the patient with painful labour and slow progress as well as for patients for trial labour after they had not progressed for some time. The latter factor has certainly influenced the rate of Caesarian sections in our group of cases.

Further well-planned studies in this respect, with larger numbers of patients and including more accurate asșessments of the progress of labour, may provide an answer to these problems. 


\section{SUMmary}

A method of producing analgesia by means of a continuous epidural technique, employing a single catheter in the upper lumbar epidural space was used in 213 obstetrical cases. In most cases the epidural analgesia was begun at the time when the patient would have required analgesic medication. During the first stage of labour a small volume of local anaesthetic agent was used to block the sensory nerve supply of the uterus; a large volume provided adequate anaesthesia of the birth canal for delivery, usually by forceps. With this method good results were obtained in 85 per cent for analgesia in labour and in 80 per cént of those cases for delivery. The high incidence of inadequate results was mainly due to errors in the management of the block, and considerable improvement is possible by better coverage with trained anaesthetists. Failures and complications have been discussed. In over 80 per cent of our cases the epidural analgesic was maintained for less than 10 hours; the longest case lasted 26 hours.

An attempt was made to evaluate the effect of continuous epidural analgesia on the duration of labour and no significant difference between these cases and the total maternity cases of our hospital was found. It is felt, however, that this comparison does not do justice to the technique, since our series was influenced by a number of patients with prolonged labour prior to the epidural analgesia; this selection also explains the higher incidence of Caesarian section.

\section{ACKNOWLEDGMENTS}

The' authors with to thank the obstetricians on the staff of both hospitals for their interest and co-operation, particularly Professor R. A. H. Kinch, Doctor H. H. Allen, and Doctor J. H. Walters.

\section{RÉSUMÉ}

Nous avons employé, dans 213 cas d'obstétrique, une méthode de produire l'analósésie au moyen dkune technique d'épidurale continue, en employant un simple cathéter dans l'espace épidural de la région lombaire haute. Dans la plupart des cas, l'analgésie épidurale a été installée au.moment où la malade aurait exigé une sédation. Au cours de la première phase du travail, nous avons employé un petit volume d'agent anesthésique local pqur bloquer l'innervation sensorielle de l'utérus; en employant un grand volume, nous avons obtenu une anesthésie adéquate pour l'accouchement, habituéllement avec forceps. L'emploi de cette méthode nous a assuré de bons résultats dans 85 pour cent des cas en ce qui concerne l'analgésie durant le travail et, dans 80 pour cent des cas en ce qui concerne l'analgésie durant l'accouchement. La grande fréquence de résultats inadéquats est due, dans la majorité de cas, à des erreurs dans la technique du blocage, et nous sommes convaincus qu'il est possible d'obtenir une amélioration 'considérable de l'analgésie par des anesthésistes d'expérience. Nous avons parlé des échecs et des complications. Dans 80 pour cent de nos cas, l'épidurale analgésique a duré moins de 10 heures; la plus longue a duré 26 heures.

Nous avons essayé de déterminer les effets de l'analgésie épidurale continue sur la durée du travail, mais nous n'avons pas trouvé de différence marquée entre ces cas et le nombre total des cas de maternité de notre hôpital. Toutefois, nous avons l'impression que cette comparaison nẹ rend pas justice à la technique 
puisque notre série a compté un nombre de malades en travail depuis longtemps avant l'analgésie épidurale; ce choix explique également la gros pourcentage de césariennes.

\section{REFERENCES}

1. Cleland, J. S. P. Paravertebral Anaesthesia in Obstetrics. Surg. Gynec. \& Obst. 57: 51 (1933).

2. Cleland, J. S. P. Continuous Peridural and Caudal Analgesia in Obstetrics. Anesth. \& Analg. 28: 61 (1949).

3. Eisen, S. M.; Rosen, N.; Winesanker, H.; Hellman, K.; Axelrod, H. J.; Totenberg, M.; Relle, A.; \& Sheffman, E. The Routine Use of Lumbar Epidural Anaesthesia in Obstetrics. Canad. Anaèsth. Soc. J. 7: 280 (1960).

4. Fleming, S. A. \& Campbell, S. M. Epidural Anaesthesia in Obstetrics. Anaesth. \& Analg. 38: 133 (1959).

5. Flowers, C. E.; Littlejohn, J. W.; \& Wells, H. B. Pharmacologic and Hypnoid Analgesia. Obst. \& Gynec. 16: 212 (1960).

6. Hehre, F. W. \& Sayig, J. M. Continuolus Lumbar Epidural Anaesthesia in Obstetrics. Am. J. Obst. \& Gynec. 80: 1173 (1960).

7. Hehre, F. W.; Sayig, J. M.; \& Lowman, R. M. Etiologic Aspects of Failure of Continuous Lumbar Peridural Anaesthesia. Anesth. \& Analg. 99: 511 (1960).

8. JARvis, S. M. Paravertebral Sympathetic Nerve Block, a Method for the Safe and Painless Conduction of Labour. Am. J. Obst. \& Gynec. 47: 335 (1944).

9. Pitkin, G. P. Conduction Anesthesia, 2nd ed., p. 750. Philadelphia: J. B. Lippincott (1953).

10. Killian, H. Lokal Anaesthesie and Lokal Anaesthetika, p. 703. Stuttgart: G. Thieme (1959). 